\title{
Dose Response for the Stimulation of Cell Division by Caffeic Acid in Forestomach and Kidney of the Male F344 Rat
}

\author{
Ursula Lutz,* Serena Lugli, $\uparrow$ Annette Bitsch,* Josef Schlatter, $\ddagger$ and Werner K. Lutz, \\ *Department of Toxicology, University of Würburg, D-97078 Würburg, Germany; †Institute of Toxicology, ETH and University of Zürich, \\ CH-8603 Schwerzenbach, Switzerland; and $\ddagger$ Swiss Federal Office of Public Health, Food Sciences Division, \\ clo Institute of Veterinary Pharmacology, CH-8057 Zurich, Switzerland \\ Received March 27, 1997; accepted June 27, 1997
}

Dose Response for the Stimulation of Cell Division by Caffeic Acid in Forestomach and Kidney of the Male F344 Rat. Lutz, U., Lugli, S., Bitsch, A., Schlatter, J., and Lutz, W. K. (1997). Fundam. Appl. Toxicol. 39, 131-137.

Caffeic acid (CA, 3,4-dihydroxycinnamic acid), at $2 \%$ in the diet, had been shown to be carcinogenic in forestomach and kidney of F344 rats and B6C3F1 mice. Based on its occurrence in coffee and numerous foods and using a linear interpolation for cancer incidence between dose 0 and $2 \%$, the cancer risk in humans would be considerable. In both target organs, tumor formation was preceded by hyperplasia, which could represent the main mechanism of carcinogenic action. The dose-response relationship for this effect was investigated in male F344 rats after 4-week feeding with $\mathrm{CA}$ at different dietary concentrations $(0,0.05,0.14,0.40$, and $1.64 \%$ ). Cells in S-phase of DNA replication were visualized by immunohistochemical analysis of incorporated 5-bromo-2'-deoxyuridine (BrdU), $2 \mathrm{hr}$ after intraperitoneal injection. In the forestomach, both the total number of epithelial cells per millimeter section length and the unit length labeling index of BrdU-positive cells (ULLI) were increased, about 2.5-fold, at 0.40 and $1.64 \%$. The lowest concentration $(0.05 \%)$ had no effect. At $0.14 \%$, both variables were decreased by about one-third. In the kidney, the labeling index in proximal tubular cells also indicated a $\mathrm{J}$-shaped (or U-shaped) dose response with a 1.8-fold increase at $1.64 \%$. In the glandular stomach and in the liver, which are not target organs, no dose-related effect was seen. The data show a good correlation between the organ specificity for cancer induction and stimulation of cell division. With respect to the dose-response relationship and the corresponding extrapolation of the animal tumor data to a human cancer risk, a linear extrapolation appears not to be appropriate. 1997 Saciety of Toxkootogy.

Caffeic acid (3,4-dihydroxycinnamic acid; CA), a natural phenolic antioxidant, is widely distributed in vegetables, fruits, and beverages (Herrmann, 1989). It occurs mainly in

\footnotetext{
1 To whom correspondence should be addressed at Department of Toxicology, University of Würburg, Versbacher Str. 9, D-97078 Wurzburg, Germany. Fax: 49-931-2013446.
}

conjugated forms. In chlorogenic acid, the most abundant derivative, the carboxylic acid function of $\mathrm{CA}$ is linked with a hydroxyl group of quinic acid.

$\mathrm{CA}$, as other polyphenols, has attracted attention for having both hazardous and beneficial effects [review (Stich, 1991)]. Administered at $2 \%$ in the diet for 2 years, CA was shown to induce hyperplasia and tumors in the forestomach and kidney of F344 rats and B6C3F1 mice (Hagiwara et al., 1991). When administered to male F344 rats after initiation with $N$-methyl- $N^{\prime}$-nitro- $N$-nitrosoguanidine (MNNG), $0.5 \%$ $\mathrm{CA}$ in the diet for 35 weeks (Hirose et al., 1991) or 1\% CA for 51 weeks (Hirose et al., 1992) increased the incidence of forestomach tumors observed after initiation with MNNG alone. Treatment of female Sprague-Dawley rats with $0.5 \%$ CA for 51 weeks after initiation with 7,12-dimethylbenz[ $a]$ anthracene also resulted in a higher incidence of forestomach tumors (Hirose et al., 1988). On the other hand, CA at $0.05 \%$ for 32 weeks inhibited the formation of squamous epithelial carcinomas of the rat tongue induced by 4-nitroquinoline-1oxide given for 5 weeks (Tanaka et al., 1993) and of mouse forestomach tumors induced by benzo(a)pyrene (at $0.54 \%$ CA) (Wattenberg et al., 1980). Thus, CA was shown to be carcinogenic at $2 \%$, tumor-promoting activity was shown at $0.5-1 \%$, and anticarcinogenic effects at $0.05-0.5 \%$.

Exposure of humans to CA strongly depends on the coffee consumption. Moderately high consumers may ingest about $9 \mathrm{mg} / \mathrm{kg}$ body wt per day. The intake from foods, mainly from tomatoes and potatoes, was estimated to be about 0.2 $\mathrm{mg} / \mathrm{kg}$ body wt per day (National Research Council, 1996). The human cancer risk, linearly extrapolated from the animal tumor data to a dose of $1 \mathrm{mg} / \mathrm{kg}$ body wt per day would result in a value as high as 1 in 1000 lives (Lutz and Schlatter, 1992). A linear extrapolation to the human exposure level might be appropriate for DNA-reactive carcinogens. For CA, this mechanism of action is unlikely. CA showed no mutagenic effects in different bacterial test systems. On the other hand, forward mutations were induced in cultured mouse lymphoma L5178Y cells, and chromosomal aberrations were induced in cultured Chinese hamster ovary cells 
(Hanham et al., 1983). In the IARC monograph on CA it was concluded that indirect genotoxicity via reactive oxygen species or tumor-promoting activity, possibly based on the stimulation of cell division, might be more relevant than DNA reactivity (IARC, 1993). For this mechanism of action, nonlinear dose-response relationships are more widely accepted. Therefore, the dose-response relationship for the stimulation of cell proliferation by CA in target and nontarget organs of the rat was investigated.

\section{MATERIALS AND METHODS}

\section{Pilot Study (BrdU Minipump for $24 \mathrm{hr}$ )}

Animals and diet. Diets were prepared by mechanical dry mixing for $1 \mathrm{hr}$ of powder maintenance diet No. 890 from Nafag AG, Gossau SG, Switzerland, with caffeic acid (Fluka; 97\% pure). Fifteen 8- to 10-weekold male F344 rats from Charles River, Savo GmbH, Kisslegg, Germany, were housed 5 to a plastic cage with hardwood chips for bedding and acclimatized for 1 week with a 12-hr light-dark cycle, control diet and tap water ad libitum.

Treatments. Animals were randomized by body weight into three groups of five and received a diet containing $0,0.2$, or $2 \%$ caffeic acid (nominal concentrations) for 4 weeks. Body weight and food consumption were measured twice weekly. At the end of the treatment, osmotic minipumps (Alzet $2001 \mathrm{D}, 8 \mu \mathrm{l} / \mathrm{hr}$, Alza Corp., Palo Alto, CA) filled with 220 $\mu \mathrm{l}$ of a solution of 5-bromo-2'-deoxyuridine (BrdU, Sigma) $[20 \mathrm{mg} \mathrm{BrdU}$ per milliliter, $10 \mathrm{~mm}$ potassium phosphate, $130 \mathrm{~mm} \mathrm{NaCl}, \mathrm{pH} 7.6$ (PBS); plus $1 \% 1 \mathrm{~N} \mathrm{NaOH]}$ were surgically implanted se over the dorsal thoracolumbar area under ether anesthesia. Incisions were closed with surgical clips. Twenty-four hours later the animals were killed following ether anesthesia, and the stomach and the first part of the small intestine were removed.

Other procedures. See "Main Study."

\section{Main Study (BrdU ip for $2 \mathrm{hr}$ )}

Diet. Powder maintenance diet Altromin 1324 (Altromin, Lage, Germany) was mixed with caffeic acid (Fluka; $97 \%$ pure) to give nominal concentrations of $0,0.066,0.2,0.66$, and $2 \%$ and pelleted without steam. The diet was prepared once and kept at room temperature. The concentration of caffeic acid in the diets was measured after extraction with methanol by RP-HPLC with UV detection (column: Partisil ODS-3, $5 \mu \mathrm{m}, 250 \times 4 \mathrm{~mm}$; solvent $\mathrm{A}: \mathrm{H}_{2} \mathrm{O} /$ trifluoroacetic acid, $\mathrm{pH} 2.0$; solvent $\mathrm{B}$ : methanol; gradient: $0-100 \%$ B in $30 \mathrm{~min}$; flow rate: $1 \mathrm{ml} / \mathrm{min}$; detection wavelength: $320 \mathrm{~nm}$ ). Based on a standard curve, the concentrations in the diets (weight per weight) were $0,0.05$ ( $76 \%$ of nominal), $0.14(70 \%), 0.40(61 \%)$, and $1.64 \%$ (82\%). There was no indication of loss of CA during storage of the diet, as indicated by reanalysis of the $0.2 \%$ (nominal) diet after the 4 -week treatment period $(0.14 \%$ measured).

Animals and treatments. Twenty-five 10-week-old male F344 rats from H. Winkelmann (Borchen, Germany) were used. To synchronize the animals with respect to a diumal cycle of cell proliferation, a well-known phenomenon in the liver which can result in large interindividual variability (Bursch and Schulte-Hermann, 1983), food was available only during the dark phase. The animals were randomized by body weight $(210-237 \mathrm{~g})$ into five groups of five animals each and given a diet containing caffeic acid at four dose levels for 4 weeks. Food consumption per cage (five animals) was measured daily and body weight twice weekly. After 4 weeks, the rats were injected ip with BrdU (Sigma, $6 \mathrm{mg} / \mathrm{ml}$ PBS; $0.5 \mathrm{ml} / 100 \mathrm{~g}$ body wt). After $2 \mathrm{hr}$ the animals were killed under ether anesthesia.

Stomach, liver, the left kidney, and the second centimeter of the duode- num were removed. The stomach was opened along the greater curvature, rinsed with PBS before weighing, and pinned flat on a cork board. Tissues were fixed in $4 \%$ neutral buffered formalin for at least $48 \mathrm{hr}$. A $3-\mathrm{mm}-$ wide strip was cut parallel to the lesser curvature of the stomach (including the forestomach). Sections of $2-4 \mathrm{~mm}$ of the left hepatic lobe and longitudinal sections of the left kidney were made.

The tissue specimens were dehydrated and embedded in paraffin, cut into $2-\mu \mathrm{m}$ sections, and mounted on 3-aminopropyltriethyloxysilane-coated slides to ensure adhesion during processing. Tissue sections were stained either with hematoxylin/eosin or immunohistochemically for BrdU.

Immunohistochemistry for BrdU. The sections were stained immunohistochemically for the incorporation of BrdU into DNA (Dietrich and Swenberg, 1991). Briefly, tissue sections were incubated with a murine monoclonal antibody to BrdU (Biogenex, San Ramon, CA), diluted 1:200, followed by biotinylated goat anti-mouse IgG (rat-adsorbed) and alkaline phosphatase-conjugated streptavidin (Super Sensitive Ready-to-Use Animal Detection Kit, Biogenex). The endogenous alkaline phosphatase activity was blocked by $5 \mathrm{~mm}$ levamisole (Sigma). Fast red (Biogenex) was used as chromagen and hematoxylin as counterstain.

The small intestine, an organ with a high cell proliferation rate, served as positive control for the BrdU systemic availability and staining. For negative controls, the primary anti-BrdU antibody was omitted.

Scoring and statistics. Tissue sections were examined microscopically for BrdU-labeled nuclei ("red cells") and unlabeled nuclei ("blue cells"). In the forestomach, the epithelium (i.e., the layer limited by the arrows shown in Fig. 2) was examined over a section length of $4 \mathrm{~mm}$ Muscularis mucosae proximal to the limiting ridge. The total number of counted cells, i.e., the sum of "red" and "blue," was between 800 (at $0.14 \%$ CA; epithelial thinning observed) and 6200 (at $1.64 \% \mathrm{CA}$; in the animal which showed the most severe hyperplasia). The counts were expressed as (i) total cells per millimeter and (ii) red cells per millimeter. The latter value is equivalent to the labeling index ULLI as defined by Monticello et al. (Monticello et $a l ., 1990$ ). Red nuclei were present uniquely in the basal cell layer of the epithelium.

In the glandular stomach, the total area of five randomly selected 0.25 $\times 0.25$-mm fields per section was scored, placing the area of replication in the center (these fields did not cover the entire thickness of the epithelium). This resulted in a count of about 2000 cells per section. The data were expressed as stated for the forestomach.

For liver and kidney, a labeling index LI was defined as the ratio "red divided by red plus blue." In the liver, an entire section $\left(80-150 \mathrm{~mm}^{2}\right)$ was evaluated for labeled hepatocytes. The resulting number was divided by the total number of hepatocytes (on average $1500 / \mathrm{mm}^{2}$ ).

In the kidney, the anatomic analysis followed described procedures (Larson et al., 1994). As many fields as necessary to score at least 60 labeled proximal tubular cells in the cortex were evaluated so that the binomial variation was not larger than the overall animal to animal variability. For the number of total proximal tubular cells per field, at least $\mathbf{4 0 0 0}$ proximal tubular cells were scored in 10 randomly selected fields.

Student's $t$ test (two-tail) was used to test for the significance of a difference between the dose groups.

\section{RESULTS}

\section{Pilot Study}

Food consumption and body weight. The animals given $\mathrm{CA}$ in the diet showed no difference in food intake or body weight gain compared to the controls. On a 4-week average, the rats consumed 18.6-19.3 g/day and the average (nominal) intakes of caffeic acid were 136 and $1386 \mathrm{mg} / \mathrm{kg}$ body wt per day for the 0.2 and $2 \%$ CA groups, respectively. 

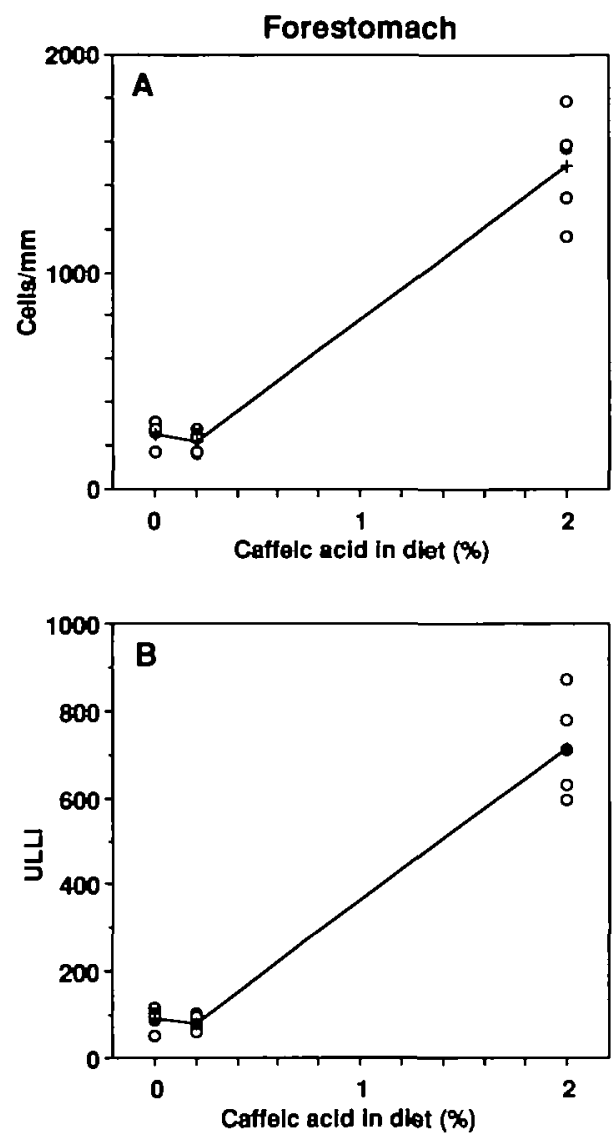

FIG. 1. Forestomach: Number of total epithelial cells per millimeter section length (A) and unit length labeling index (ULLI, number of BrdUpositive cells per millımeter section length) (B) in the forestomach of male F344 rats, after 4 weeks of feeding with caffeic acid at different dietary concentrations. $O$, individual animals; + , mean value $(n=5)$. Pilot study: BrdU was administered via sc implanted osmotic pump for 24 hr. $p<$ 0.0001 for 0 vs $2 \%$ CA (A and B; Student's $t$ test).

Cell proliferation. The number of total cell $\mathrm{s} / \mathrm{mm}$ and the "unit length labeling index" ULLI in the forestomach are shown in Figs. 1A and 1B. Treatment with $0.2 \% \mathrm{CA}$ had no effect. At $2 \% \mathrm{CA}$, the ULLI and the number of total cells $/ \mathrm{mm}$ were significantly increased by factors of $6-$ and 8 -fold, respectively.

When analyzed in terms of the labeling index LI, values of $36.0,37.9$, and $48.5 \%$ were derived for the $0,0.2$, and $2 \%$ CA groups, respectively. The high value in the control group indicates that the availability of $\mathrm{BrdU}$ for as long as $24 \mathrm{hr}$ allowed a large fraction of the epithelial cells to incorporate BrdU, so that little space for the detection of a treatment-related increase was left. This was accounted for under the experimental conditions chosen for the main study.

\section{Main Study}

For the main study, BrdU pulse labeling was used, with sacrifice $2 \mathrm{hr}$ after ip injection. A larger number of dose groups was included, to cover the entire dose range observed for carcinogenic, tumor-promoting, and anticarcinogenic effects of CA. In addition, the kidney, another target organ for tumor induction, as well as liver and glandular stomach, two nontarget organs, was investigated.

Food consumption and body weight. The animals given $\mathrm{CA}$ in the diet showed no difference in food consumption or body weight gain compared to the controls. They consumed the same amount of food as in the pilot study. The doses of CA were $35,100,269$, and $1147 \mathrm{mg} / \mathrm{kg}$ body wt per day for the $0.05,0.14,0.4$, and $1.64 \%$ groups, respectively.

Pathology. Macroscopically, the forestomach of three rats given $1.64 \% \mathrm{CA}$ and two rats given $0.4 \% \mathrm{CA}$ showed coating with a grey-white material. In the $1.64 \% \mathrm{CA}$ group, the forestomach of one rat was covered with striped hemorrhage; one rat showed one point hemorrhage. The forestomach of the rats given $0.14 \%$ CA appeared thinner and was difficult to section. No gross pathological alterations were seen in the forestomach of the remaining animals.

Microscopically, $1.64 \%$ CA induced severe hyperplasia of the epithelium ( $>0.5 \mathrm{~mm}$ thickness) and hyperkeratosis in the forestomach of one rat, moderate hyperplasia $(0.1-$ $0.5 \mathrm{~mm})$ in two, mild $(<0.1 \mathrm{~mm})$ in one, and none in one rat. There was a pronounced difference between the individual animals in this dose group. In the $0.4 \%$ CA group, moderate hyperplasia and hyperkeratosis were observed in all animals (Fig. 2C). In the $0.14 \%$ CA group, the macroscopic observation of a thinner forestomach wall (in relation to the controls) was confirmed in all animals (Fig. 2B). There was no histopathological alteration in the $0.05 \% \mathrm{CA}$ group or in the control group (Fig. 2A).

In glandular stomach, liver, and kidney, no histopathological changes were observed.

Cell proliferation. One rat in the control group did not show detectable BrdU labeling in any organ; the reason is unknown. This animal was excluded. In the forestomach, the total number of cells $/ \mathrm{mm}$ and the ULLI as a function of dose are shown in Figs. 3A and 3B, respectively. The lowest dose group $(0.05 \% \mathrm{CA})$ was not different from control. The $0.14 \%$ CA group showed a decrease of about a third in both total cells/mm $(p<0.0006)$ and the ULLI $(p<0.06)$. This finding is in agreement with the microscopic observation of a thin lining. The group given $0.4 \%$ CA showed a 2.5 -fold increase and both values, labeled and total cell numbers per millimeter, were significantly different from controls. In the highest dose group $(1.64 \% \mathrm{CA})$ the interindividual difference was very large. The values obtained for the individual rats paralleled the microscopic observations in that the top cell number was seen in the animal with the most severe hyperplasia. Compared with the second highest dose group, no further increase was achieved on average. The biological response appeared to be saturated at $0.4 \% \mathrm{CA}$ already. 

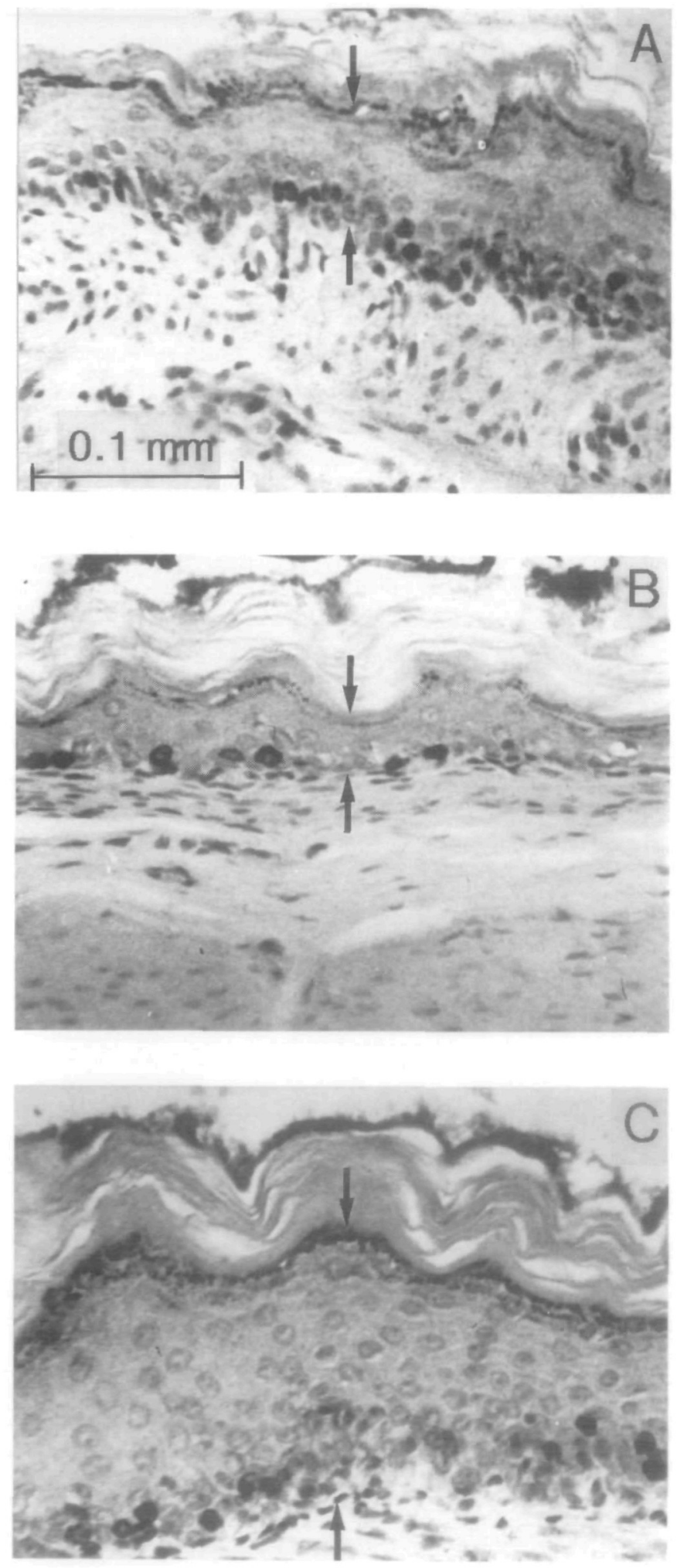

FIG. 2. Forestomach: Histological observations in the forestomach of male F344 rats, after 4 weeks of feeding with caffeic acid in the diet at 0 ( $\mathrm{A}$, control), $0.14 \%$ (B, thinning), and $0.4 \%$ (C, moderate hyperplasia). The epithelial layer is marked by arrows.
In the glandular stomach (Figs. $4 \mathrm{~A}$ and $4 \mathrm{~B}$ ), no CA doserelated effects were seen. This is in agreement with the fact that the glandular stomach is not a target organ for tumorigenicity of CA. The same holds for the liver where the data are expressed as labeling indices for hepatocytes (Fig. 5). The LI in the control group was $0.29 \pm 0.12(n=$ 4). Labeled hepatocytes were evenly distributed over the entire section without zonal differences.

The LI in the proximal tubules of the kidney was 0.18 $\pm 0.03(n=4)$ for controls. It was significantly increased by a factor of 1.8 in the highest dose group (Fig. 6). A numerical increase was seen in the second highest dose, while $0.14 \%$ CA had no effect. The decrease seen at $0.05 \%$ was borderline significant ( $p=0.085$ for the two-tailed Student $t$ test).
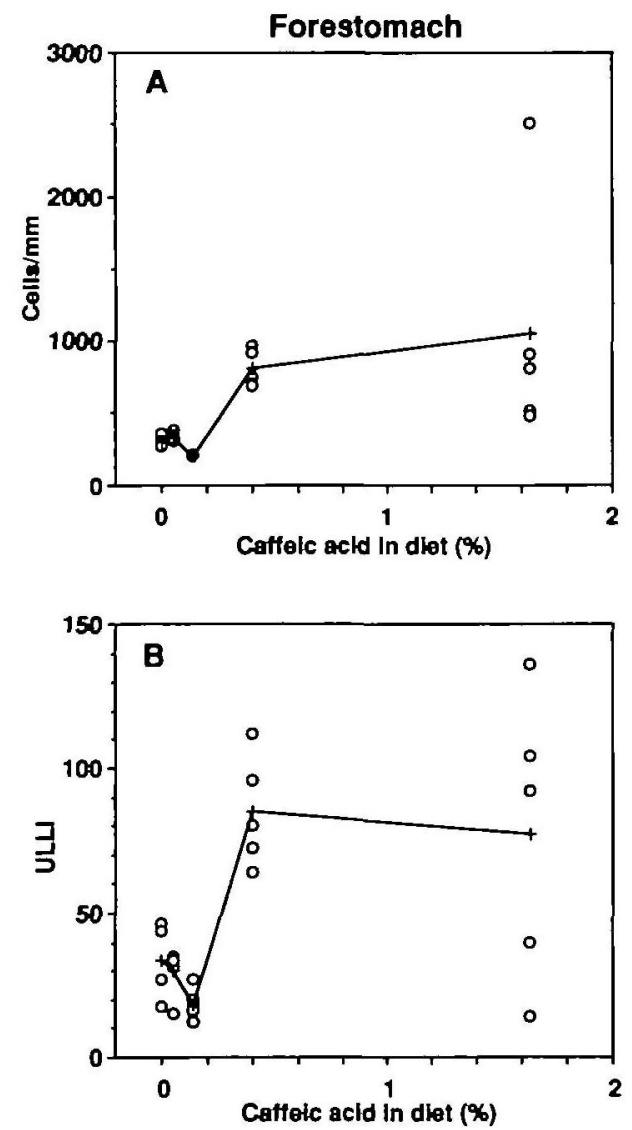

FIG. 3. Forestomach: Number of total epithelial cells per millimeter section length (A) and unit length labeling index (ULLI, number of BrdUpositive cells per millimeter section length) (B) in the forestomach of male F344 rats, after 4 weeks of feeding with caffeic acid at different dietary concentrations. $O$, individual animals; + , mean value $[n=5$ (4 in control group)]. BrdU was administered via ip injection $2 \mathrm{hr}$ before killing. Student's $t$ test (two-tailed): 0 vs $0.4 \% \mathrm{CA}, p<0.0001$ for $\mathrm{A}$ and $p<0.003$ for $\mathrm{B}$ (increase); 0 vs $0.14 \% \mathrm{CA}, p<0.0006$ for $\mathrm{A}$ and $p<0.06$ for $\mathrm{B}$ (decrease). 

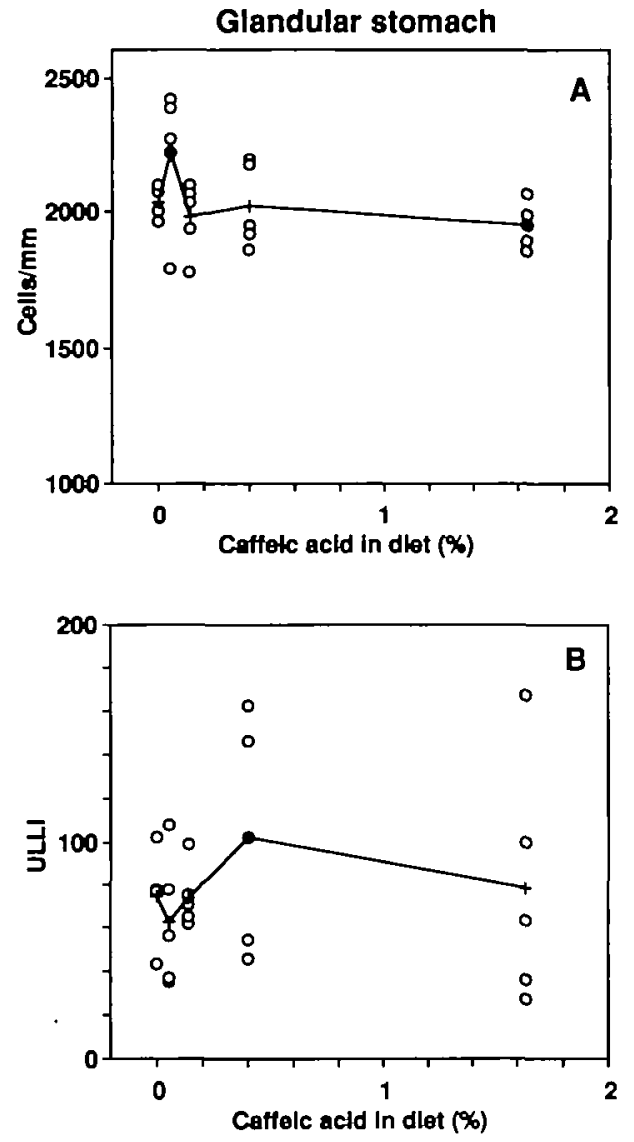

FIG. 4. Glandular stomach: Number of cells per millimeter section length (A) and unit length labeling index (ULLI, number of BrdU-positive cells per millimeter section length) (B) in the glandular stomach of male F344 rats, after 4 weeks of feeding with caffeic acid at different dietary concentrations. $\bigcirc$, individual animals; + , mean value $[n=5$ ( 4 in control group)]. BrdU was administered via ip injection $2 \mathrm{hr}$ before killing.

\section{DISCUSSION}

The stimulation of cell proliferation has become a widely accepted intermediate endpoint for nongenotoxic carcinogenesis (Butterworth et al., 1991, 1992; Clayson et al., 1991; Cohen et al., 1991; Jones et al., 1996; Monticello et al., 1996). Dividing cells are "cells at risk," due to a higher probability to accumulate mutations from primary DNA lesions and to loose heterozygosity for tumor suppressor genes by mitotic recombination. The perfect concordance shown here between target organs for tumor induction and target organs for increased number of cell divisions indicates that this mechanism of action may contribute to the tumorigenicity of caffeic acid.

In the forestomach, Kagawa et al. (Kagawa et al., 1993) and Ito et al. (Ito et al., 1993) noted increased cell proliferation, elevated DNA synthesis, and hyperplasia to parallel

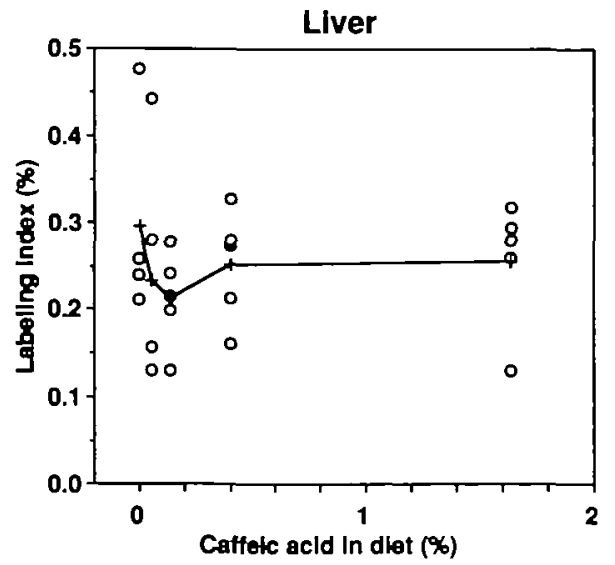

FIG. 5. Liver: BrdU labelıng index in the liver of male F344 rats, after 4 weeks of feeding with caffeic acid at different dietary concentrations. $O$, individual animals; + , mean value $[n=5$ (4 in control group)]. BrdU was administered via ip injection $2 \mathrm{hr}$ before killing.

carcinogenesis by $\mathrm{CA}$. The authors concluded that $\mathrm{CA}$ acted primarily as mitogen, with regeneration due to toxicity further enhancing cell proliferation (Ito et al., 1993). In the present study, 4-week exposure resulted in an increase of both the total number of cells per millimeter section length and the number of S-phase cells only at the highest two dose levels $(0.4$ and $1.64 \%)$. The cell proliferation data were fully supported by the histopathological findings of severe or moderate hyperplasia and hyperkeratosis. While the lowest dose $(0.05 \% \mathrm{CA})$ produced no effect at all, the data seen at $0.14 \%$ were unexpected. The number of both total cells and S-phase cells was decreased, compared to the controls. This was

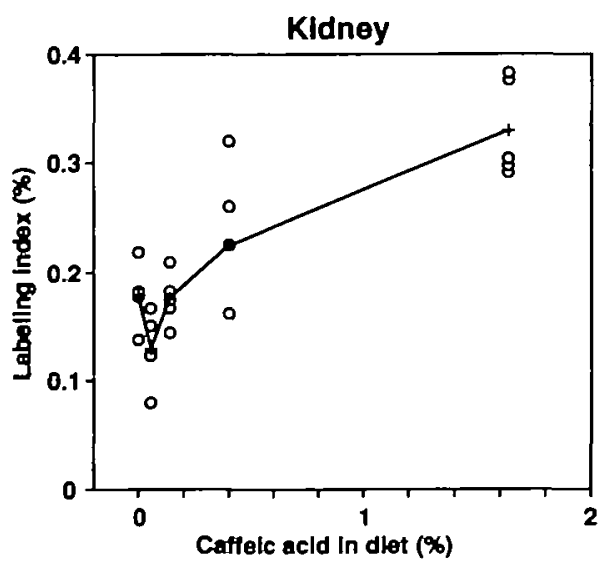

FIG. 6. Kidney: BrdU labeling index in proximal tubular cells in the kidney of male F344 rats, after 4 weeks of feeding with caffeic acid at different dietary concentrations. $O$, individual animals; + , mean value $[n$ $=5$ (4 in control group)]. BrdU was administered via ip injection $2 \mathrm{hr}$ before killing. $p<0.0004$ for 0 vs $1.64 \%$ CA (increase); $p=0.085$ for 0 vs $0.05 \%$ CA (decrease; two-tailed Student's $t$ test). 
paralleled by the observation of extremely thin forestomach tissue layers. This low-dose phenomenon of delayed cell division could also explain some of the cancer-protective effects described in the Introduction.

In the kidney, the other target organ of CA-induced carcinogenesis in the rat (Hagiwara et al., 1991), the labeling index for cells of the proximal tubules was increased only at the highest dose level. As seen in the forestomach, the dose-response curve showed a J shape. However, the decrease at low dose was only borderline significant. In the glandular stomach and in the liver, no CA-induced effects were detected.

The measures of cell division in the control animals were in perfect agreement with the recently published values for various cancer target tissues of male and female F344 rats and B6C3F1 mice (Eldridge and Goldsworthy, 1996). Labeling indices LI of 0.23 and 0.17 in male F344 rat liver and kidney, respectively, and a ULLI value of $35 \pm 12$ in the forestomach were reported for an age range of 7 to 20 weeks. The determination of S-phase cells by immunohistochemical labeling after a 2-hr BrdU pulse appears to show little variability between laboratories, if performed under identical conditions. In addition to methodical feasibility, the data show a good correlation between those organs that show sustained stimulated cell division at subchronic treatment and susceptibility with respect to tumor development in longterm studies.

Human exposure to CA occurs predominantly as chlorogenic acid, an ester formed between $\mathrm{CA}$ and a hydroxyl group of quinic acid (Herrmann, 1989). In a 4-week feeding study with $2 \%$ chlorogenic acid, no effect on the rat forestomach was observed (Hirose et al., 1987), while CA tested in parallel produced pronounced hyperplasia throughout the forestomach epithelium.

Humans have no forestomach. For a cancer risk assessment, the situation in the kidney might be more relevant. The question to what extent CA from chlorogenic acid becomes available systemically has been addressed in the rat and in humans. After oral administration, no chlorogenic acid was detectable in urine (Booth et al., 1957). Therefore, the following risk assessment is based on the worst-case assumption that all CA ingested as chlorogenic acid becomes available systemically.

In the carcinogenicity study with $2 \%$ CA (Hagiwara et al., 1991), the induction of tubular cell adenoma in the kidney of male rats (4/30) and female mice (8/30) was strongly correlated with tubular cell hyperplasia (21/30 and 28/30, respectively). If hyperplasia is the dominant factor in the process of kidney tumor induction, only doses that result in a sustained increase of cell division would constitute a cancer risk. In the present study, the lowest dietary concentration that produced a slight increase in the labeling index was $0.4 \%$, which was equivalent to a dose of $270 \mathrm{mg} / \mathrm{kg}$ body wt per day. The decrease of the labeling index responsible for the $J$ shape of the dose-response curve was observed at $0.05 \%$ (35 mg/ $\mathrm{kg}$ body wt per day). Therefore, even for strong coffee drinkers who might ingest up to $10 \mathrm{mg} \mathrm{CA} / \mathrm{kg}$ body wt per day (predominantly in the form of chlorogenic acid), the exposure would be in the range of potential protection rather than potential harm, in terms of the effects on the rate of cell division, and under the assumption that the data can be extrapolated from rat to human.

On the basis of all data combined it is concluded that the cancer risk for humans associated with the dietary intake of caffeic acid might be negligible.

\section{ACKNOWLEDGMENTS}

This work was supported by the Swiss Federal Office of Public Health (BAG Grant FE 316.96.0551). The authors thank Drs. Ch. Gembardt and R. Bahnemann, BASF, Ludwigshafen, Germany, for their help with the pathological and immunohistochemical examinations and critucal review of the manuscript and Mrs. I. Fenske, Institute of Pathology of the University of Wurzburg, for the histological preparations.

\section{REFERENCES}

Booth, A. N., Emerson, O. H., Jones, F. T., and DeEds, F. (1957). Urinary metabolites of caffeic and chlorogenic acids. J. Biol. Chem. 229, 51-59.

Bursch, W., and Schulte-Hermann, R. (1983). Synchronization of hepatic DNA synthesis by scheduled feeding and lighting in mice treated with the chemical inducer of liver growth alpha-hexachlorocyclohexane. Cell Tissue Kinet. 16, 125-134.

Butterworth, B. E., Popp, J. A., Conolly, R. B., and Goldsworthy, T. L. (1992). Chemically induced cell proliferation in carcinogenesis. IARC Sci. Publ. 116, 279-305.

Butterworth, B. E., Slaga, T. J., Farland, W., and McClain, M. (1991). Chemically Induced Cell Proliferation Implications for Risk Assessment, Wiley-Liss, New York.

Clayson, D. B., Iverson, F., Nera, E. A., and Lok, E. (1991). Early indicators of potential neoplasia produced in the rat forestomach by non-genotoxic agents: The importance of induced cellular proliferation. Mutat. Res. 248, 321-331.

Cohen, S. M., Purtilo, D. T., and Ellwein, L. B. (1991). Pivotal role of increased cell proliferation in human carcinogenesis. Modern Pathol. 4, 371-382.

Dietrich, D. R., and Swenberg, J. A. (1991). The presence of alpha-2uglobulin is necessary for d-limonene promotion of male rat kidney tumors. Cancer Res. 51, 3512-3521.

Eldridge, S. R., and Goldsworthy, S. M. (1996). Cell proliferation rates in common cancer tissues of $\mathrm{B} 6 \mathrm{C} 3 \mathrm{Fl}$ mice and $\mathrm{F} 344$ rats: Effects of age, gender, and choice of marker. Fundam. Appl. Toxicol. 32, 159-167.

Hagiwara, A., Hirose, M., Takahashi, S., Ogawa, K., Shirai, T., and Ito, N. (1991). Forestomach and kidney carcinogenicity of caffeic acid in F344 rats and C57BL/6N $\times$ C3H/HeN F1 mice. Cancer Res. 51, 5655-5560.

Hanham, A. F., Dunn, B. P., and Stich, H. F. (1983). Clastogenic activity of caffeic acid and its relationship to hydrogen peroxide generated during autooxidation. Mutat. Res. 116, 333-339.

Herrmann, K. (1989). Occurrence and content of hydroxycinnamic and 
hydroxybenzoic acid compounds in foods. Crit. Rev. Food Sci. Nutr. 28(4), 315-347.

Hirose, M., Kawabe, M., Shibata, M., Takahashi, S., Okazaki, S., and Ito, $N$. (1992). Influence of caffeic acid and other o-dihydroxybenzene derivatives on $\mathrm{N}$-methyl- $\mathrm{N}^{\prime}$-nitro- $\mathrm{N}$-nitrosoguanidine-intiated rat forestomach carcinogenesis. Carcinogenesis 13(10), 1825-1828.

Hirose, M., Masuda, A., Fukushima, S., and Ito, N. (1988). Effects of subsequent antioxidant treatment on 7,12-dimethylbenz(a)anthracene-initiated carcinogenesis of the mammary gland, ear duct and forestomach in Sprague-Dawley rats. Carcinogenesis 9(1), 101-104.

Hirose, M., Masuda, A., Imaida, K, Kagawa, M., Tsuda, H., and Ito, N. (1987). Induction of forestomach lesions in rats by oral administrations of naturally occurring antioxidants for 4 weeks. Jpn. J. Cancer Res. 78, 317-321.

Hirose, M., Mutai, M., Takahashi, S., Yamada, M., Fukushima, S., and Ito, N. (1991). Effects of phenolic antioxidants in low dose combination on forestomach carcinogenesis in rats pretreated with $\mathrm{N}$-methyl- $\mathrm{N}^{\prime}$-nitro- $\mathrm{N}$ nitrosoguanidine. Cancer Res. 51, 824-827.

IARC (1993). Some naturally occurring substances: Food items and constituents, heterocyclic aromatic amines and mycotoxins. In IARC Monographs, Vol. 56, pp. 115-134.

Ito, N., Hirose, M., and Takahashi, S. (1993). Cell proliferation and forestomach carcinogenesis. Environ. Health Perspect. 101(Suppl. 5), 107-110.

Jones, H. B., Eldridge, S. R., Butterworth, B. E., and Foster, J. R. (1996). Measures of cell replication in risk/safety assessment of xenobiotic-induced, nongenotoxic carcinogenesis. Regul. Toxicol. Pharmacol. 23, 117-127.
Kagawa, M., Hakoi, K., Yamamoto, A., Futakuchi, M., and Hirose, M. (1993). Comparison of reversibility of rat forestomach lesions induced by genotoxic and non-genotoxic carcinogens. Jpn. J. Cancer Res. 84(11), $1120-1129$.

Larson, J. L., Wolf, D. C., and Butterworth, B. E. (1994). Induced cytolethality and regenerative cell proliferation in the livers and kidneys of male B6C3F1 mice given chloroform by gavage. Fundam. Appl. Toxicol. 23, 537-543.

Lutz, W. K., and Schlatter, J. (1992). Chemical carcinogens and overnutrition in diet-related cancer. Carcinogenesis 13, 2211-2216.

Monticello, T. M., Morgan, K. T., and Hurtt, M. E. (1990). Unit length as the denominator for quantitation of cell proliferation in nasal epithelia. Toxicol. Pathol. 18, 24-31.

Monticello, T. M., Swenberg, J. A., Gross, E. A., Leininger, J. R., Kimbell, J. S., Seilkop, S., Starr, T. B., Gibson, J. E., and Morgan, K. T. (1996). Correlation of regional and nonlinear formaldehyde-induced nasal cancer with proliferating populations of cells. Cancer Res. 56, 1012-1022.

National Research Council (1996). Carcinogens and Anticarcinogens in the Human Diet. National Academy Press, Washington, DC.

Stich, H. F. (1991). The beneficial and hazardous effects of simple phenolic compounds. Mutat. Res. 259, 307-324.

Tanaka, T., Kojima, T., Kawamori, T., Wang, A., Suzui, M., Okamoto, K., and Mori, H. (1993). Inhibition of 4-nitroquinoline-1-oxide-induced rat tongue carcinogenesis by the naturally occurring plant phenolics caffeic, ellagic, chlorogenic and ferulic acids. Carcinogenesis 14(7), 1321-1325.

Wattenberg, L. W., Coccia, J. B., and Lam, L. K. T. (1980). Inhibitory effects of phenolic compounds on benzo(a)pyrene-induced neoplasia. Cancer Res. 40, 2820-2823. 